\title{
An e-Learning Course on the Patient-Centered Approach to Colorectal Cancer Screening: GPs First Choice!
}

\section{Amélie Aïm-Eusébi ( $\nabla$ amelie.aim-eusebi@u-paris.fr )}

Université de Paris

\section{Antoinette Bouziane}

Sorbonne Paris Cité

Karima Sekri

Université de Paris

Bernard Clary

Université de Montpellier

Bernard Freche

Université de Poitiers

Julien Le Breton

Université Paris Est Créteil

Isabelle Aubin-Auger

Université de Paris

\section{Research Article}

Keywords: colorectal cancer, screening, family practice, e learning

Posted Date: September 27th, 2021

DOl: https://doi.org/10.21203/rs.3.rs-911819/v1

License: (9) This work is licensed under a Creative Commons Attribution 4.0 International License. Read Full License 


\section{Abstract}

BACKGROUND: Colorectal cancer (CRC) is the third most common cancer in men and the second in women worldwide. During the period 2017-2018, in France, 32.1\% of the eligible population completed screening, which is under the acceptable uptake rate. The FORCEPS study aimed to test whether a training program focused on improving general practitioners' (GPs') communication skills could increase their patients' CRC screening rate. Our study reports on the construction of, participation in and evaluation of the e-learning training program tested in the FORCEPS study.

METHODS: An interdisciplinary team designed an e-learning program for French GPs on the Moodle ${ }^{\circledR}$ platform. Learning activities related to the stated learning objectives and interactive approaches were specified. Two sessions took place, in May and November 2018. The training lasted 6 weeks.

RESULTS: In all, 116 GPs registered for the training program. Seventy per cent of the GPs who registered for the first session opted to follow the training via e-learning rather than in person. Among the participants, $36.0 \%$ followed the training in its entirety during session 1 , as did $24.0 \%$ during session 2 . At the end of the training, none of the participating GPs self-assessed themselves as a "novice", and the number of GPs self-assessing as "intermediate" or "experienced" increased. Overall, $62.9 \%$ of the participants were generally satisfied with the e-learning course.

CONCLUSIONS: The web-based program focused on improving GPs' communication skills to encourage CRC screening was chosen by a large majority of the participating GPs and received positive reviews. While GPs' theoretical knowledge can be improved through our training program, it remains to be seen whether or not this will be reflected in their everyday practice, thus resulting in an increased CRC screening participation rate among patients.

\section{Background}

Colorectal cancer (CRC) is the third most common cancer in men and the second in women worldwide. Different screening strategies have been developed, including stool-based tests to detect occult blood in feces, endoscopic methods (sigmoidoscopy, colonoscopy, etc.) and computed tomographic colonography. A two-step strategy, beginning with a fecal immunologic test every two years for the average risk population 50-74 years old and followed by a colonoscopy if test comes out positive, has been used in France since 2015, following a six-year period of screening using a stool guaiac test [1]. This screening strategy has proven effective in reducing CRC mortality with a positive benefit-harm ratio [2]. During the period 2017-2018, almost 5.5 million participants completed the screening, accounting for a participation rate of $32.1 \%$, which is under the acceptable uptake rate of $45 \%$ and the desirable level of $65 \%$ specified by European guidelines [3].

Various strategies are used to encourage the target population to take part in CRC screening programs, including consultations with general practitioners (GPs) or invitations by direct mail including a sampling kit. In France, the screening test is delivered mainly through GPs. Previous studies have explored GP and 
patient barriers and facilitators, as well as the ways GPs delivered the test. The results support targeted actions to improve participation in specific patient populations, namely patients under 60 years of age, males, and patients living in socioeconomically deprived areas. In contrast, actions to enhance the effectiveness of GPs in maximizing patient participation should be aimed at the overall GP population rather than targeting specific groups of physicians [4]. In order to increase the CRC screening participation rate, patient-centered communication must be improved. A previous study combined qualitative data from several research projects, enabling the development of educational materials to improve physicianpatient communications. One component of these tools focused specifically on the Patient-Centered Clinical Method [5]. In 2011, a pilot study was conducted with a half-day program in order to get GPs involved more easily. At the end of the study period, $17 \mathrm{GPs}$ (from 16 practices) in the intervention group and $28 \mathrm{GPs}$ (from 19 practices) in the control group were still active and sent in their data. This intervention focusing on doctor-patient communication showed efficacy in improving patient participation [6]. Based on these data, and to achieve better implementation, we wanted to test other educational materials, such as online videos and e-learning. E-learning offers participants a number of advantages; including lower costs and the freedom to choose the right place and right time for their training [7]. However, potential disadvantages include the lack of communication and sharing with other learners and the teacher, as well as lower motivation to learn.

In this context, the FORCEPS study was set up in order to test whether an intervention focused on improving GPs' communication skills could increase their patients' CRC screening rate and to let the GPs choose the type of training they preferred, with either remote (e-learning) or face-to-face sessions. This article reports on the construction of, participation in and evaluation of the training program tested in the FORCEPS study.

\section{Methods}

\section{Participants}

The target audience for our e-learning program was composed of GPs from 14 French départements (counties) selected for the study. They were recruited by e-mail 2018 with the help of local coordinators using the contact lists for various French GP scientific associations. The GPs then had to register via an online computer platform where they chose to do the training in person or via e-learning. At this point, they also had to enter some personal information.

\section{E-learning development team}

An interdisciplinary team, including GPs employed at a medical school, educational advisors, instructional design engineers and audio-visual professionals, developed the e-learning program.

\section{Design}

Design of the e-learning program lasted from January 2016 to April 2018. Two sessions took place, one in May 2018 and one in November 2018. The e-learning program was hosted on the Moodle® platform. 
The outcome-oriented learning activities were, to the greatest possible extent, based on an interactive approach in order to encourage participant input and dialogue with trainers [7]. The goal was to increase participant motivation and therefore attendance.

\section{Training}

The training course lasted 6 weeks. During week zero, participants had to position themselves on an interactive map of France as well as determine their level of knowledge on CRC screening. Week one involved identifying barriers to screening through brainstorming sessions in groups of 6 to 7 participants. Week two identified screening strategies adapted to each patient and participants were asked to solve clinical cases. Week three focused on how to conduct a test delivery consultation tailored to each patient: this session featured a video showing an example consultation and a subsequent group discussion on the content of the video. Week four explored the patient-centered approach in CRC screening, and participants watched a video showing various example consultations, with on-screen commentary from a GP with expertise in the approach. Participants were asked to identify elements related to the patientcentered approach in this video. Week five aimed to transpose elements of the patient-centered approach to other care situations. Participants worked on clinical cases to apply the patient-centered approach and assessed their peers' work. Reminder e-mails were sent to the participants before each new session. At the end of the course, the participants had to once again determine their level of knowledge and to complete an evaluation questionnaire. Halfway through the course, an online "classroom session" was held, enabling participants to meet each other and the facilitators virtually. At the end of each week, documents related to the topic of the week (bibliographies, summaries, tools, etc.) were made available to participants. There was no deadline for completing the assignments over the weeks and, with the limited amount of group work, participants could work whenever they wished.

\section{Results}

\section{Participants and attendance rate}

In all, 116 GPs registered for the training course. Fifteen GPs $(12.9 \%)$ chose to do the training in person and were split up into 3 sessions with 5 participants each. One hundred one GPs (87.1\%) registered for the training course via e-learning, with 70 GPs signing up for the first e-learning session and $31 \mathrm{GPs}$ enrolling in the second one. Seventy per cent of the GPs registered for the first session opted to follow the training via e-learning rather than in person. Due to insufficient registration for the in-person courses, the GPs enrolled in the second session were not given the opportunity to choose, and all did the course via elearning. We have made a distinction between "registrants", "starters", "participants" and "finishers". While "registrants" are those GPs who signed up for the training program, "starters" are defined as those who registered for the training course and actually logged on to the e-learning platform at least once.

"Participants" are those who completed at least one of the activities. "Finishers" are those who completed the training program in its entirety. 
Eighty-three starters (82.2\%) logged on to the platform at the beginning of the training course, i.e. 58 $(82.9 \%)$ during the first session and $25(80.6 \%)$ during the second session. Overall, $36.0 \%$ of the starters (21 out of 58) during session 1 and $24.0 \%$ (6 out of 25) during session 2 followed the training course in its entirety. During session 1, 39.7\% of the starters (23 out of 58 ) took part in the virtual "classroom session", as did $32.0 \%$ (8 out of 25 starters) during session 2 .

Among the 76 participants in the e-learning program, $63.2 \%$ were women, $7.9 \%$ were under 30 years old, $48.7 \%$ were between 30 and 40 years old, $23.7 \%$ were between 40 and 50 years old and $19.7 \%$ were over 50 years old. Overall, $67.1 \%$ had never had any previous training on colorectal cancer screening, i.e. 37 out of 58 participants (63.8\%) for session 1 and 14 out of 18 (77.8\%) for session 2. As well, $72.4 \%$ had never had any prior training on the patient-centered approach, i.e. 40 out of 58 participants $(69 \%)$ for session 1 and 15 out of 18 (83.3\%) for session 2 .

\section{Motivation for the topic and e-learning (Week 0, Activity 2)}

In all, $38.6 \%$ of the participants (27 out of 70 ) explained that they had decided to take part in this training to improve their practice and $37.1 \%$ (26 out of 70 ) stated they wished to increase patients' participation in colorectal cancer screening. As well, $37.1 \%$ (26 out of 70 ) said that they chose e-learning because it was easier to organize, $28.6 \%$ (20 out of 70 ) claimed it suited their needs in terms of time and availability and $7.1 \%$ (5 out of 70 ) chose the remote format in order to discover something new or out of curiosity (Fig. 1).

\section{Self-assessment (Week 0, Activity 3 and Week 6, Activity 1)}

While 7 out of 64 GPs (10.9\%) had self-assessed as "novices" at the beginning of the study, none did so at the end. At the beginning of the training, 35 of the 64 participants $(54.7 \%)$ declared themselves as "intermediate", 21 as "experienced" (32.8\%) and 1 as an "expert" (1.6\%). At the end of the training, 6 of the 27 finishers (22.2\%) declared themselves as "intermediate", 17 (63.0\%) as "experienced" and 4 (14.8\%) as "experts". We observed an overall increase in self-reported skill level, from "intermediate" to "experienced" (with a $30.2 \%$ increase in the number of "experienced" GPs at the end of the training) and from "experienced" to "expert" (with an 13.2\% increase in the number of "experts" at the end of the training).

\section{Satisfaction (Week 6, Activity 2)}

Overall, $62.9 \%$ of the finishers (17 out of 27 ) were generally satisfied with the e-learning course. The elearning program met the expectations of $59.3 \%$ of the finishers (16 out of 27 ), and $55.6 \%$ of the finishers (15 out of 27) would recommend it to a colleague. The most satisfying point for the finishers was the clarity of the stated objectives ( $96.3 \%$, i.e. 26 out of 27 ). In all, $77.8 \%$ of the finishers ( 21 out of 27 ) reported that they appropriated knowledge during the e-learning course while $63 \%$ (17 out of 27) felt they gained new knowledge about colorectal cancer screening and the patient-centered approach. Using the website was not easy for $59.3 \%$ of the finishers (16 out of 27) (Fig. 2).

\section{Discussion}




\section{Main results}

The web-based program on improving GPs' communication skills with regard to CRC screening was chosen by a large majority of the GPs who volunteered to participate in the FORCEPS study. Among the GPs who registered, two thirds actually participated and, of these, one third completed the 6-week program. In the end, the program received favorable evaluations, with an increase in knowledge and skills in our study.

\section{Strengths and limitations}

The main strength of the study was its originality, thanks to its dual focus on developing GPs' knowledge and communication skills in the area of CRC screening. To our knowledge, this was the first program using such a design. The interdisciplinary educational team attempted to avoid the potential disadvantages of remote learning. Interactive methods were developed to help maximize discussion and sharing with other learners and the instructor as well as to increase the motivation to learn. First, a brainstorming session in groups of 6 to 7 participants during week 2 proved useful in building an elearning community. Next, an online "classroom session" held halfway through course improved the relationship with the educational team. As patient-centered communication can be used in many other care situations, the trained GPs can use the skills developed in a wide variety of other healthcare contexts. Additionally, our training program can be further developed and tailored to a number of other care situations [8;9].

Our work does have several limitations. Firstly, though the GPs came from many different French départements (counties), younger physicians and females tended to be overrepresented with respect to the overall population of French GPs [10]. While e-learning was well-received compared to face-to-face training, only a quarter of those who registered actually completed the program. But, the current average completion rate for MOOCs is approximately 2 to $10 \%$ in higher education according to previous studies [11]. The initial feeling that training via e-learning was easier to organize gradually eroded over time as it required a significant long-term investment ( 6 weeks) to meet the same objectives as face-to-face training. This will result in a "lost to follow-up" effect for the intention-to-treat analysis of the randomized controlled trial and a loss of power for the per protocol analysis. Additionally, some GPs reported difficulties with the website support (Moodle $\left.{ }^{\circledR}\right)$. During week five, the participants were unable to take the course due to a computer glitch. During the second session, some participants had no other choice than to take the e-learning course: the face-to-face sessions were cancelled, as the minimum required number of five registered participants had not been reached.

\section{Prospects}

The use of e-learning in continuous medical education has increased and requires high standards of quality. As well, while knowledge can be improved, little is known on whether positive changes actually result in day-to-day practice [12]. In our study, the majority of GPs opted for the e-learning format over 
face-to-face training. This supports findings in the medical literature on the choice of e-learning thanks to time savings and easier overall organization [7].

A systematic review has identified the factors which impact on e-learning: interaction and collaboration between learners and facilitators; considering learners' motivation and expectations; utilizing user-friendly technology; and putting learners at the center of pedagogy [13]. Our e-learning experience confirms the importance of these factors particularly on attendance. They are ways to make our e-learning more attractive according to these elements. First of all the technical aspect: One key element is the website support; we recommend to choose one easy to use. A short video to explain how to use the website could be useful: for example how to download and save a file. Participants should also have the opportunity to contact a computer technician. But also the time table: we suggest to respect the agenda as far as possible and to send it early to the participants; Email or telephone reminders should be sent before each new activity. Then the educational aspect: Interactive methods are much more appreciated than simple slides with comments. A virtual classroom in the middle of the course might revive interest. At least, the motivational aspect: stimulating learner motivation could be a key factor. Incentives like credit points for continuous medical education could stimulate participants to achieve the course.

A systematic review of randomized trials assessing the effectiveness of e-learning versus traditional learning for health professionals did not find evidence that e-learning could improve their skills or knowledge [7]. Traditional learning may be preferable in small groups of GPs when physical attendance is feasible, while e-learning programs may be a better choice when the aim is to reach a large number of GPs at a limited cost, as for CRC screening programs. The second phase of the FORCEPS study will assess patient outcomes in addition to GPs' skills and knowledge, using a randomized design to assess the CRC screening participation rate.

In the current health context, it is interesting to develop e-learning since there is a more frequent use of this type of training for continuous and initial medical education.

Evidence is needed to continue web-based programs and to compare those courses with face-to-face sessions. Communication skills also seem to be a particularly suitable focus for web-based courses when they are geared towards a specific topic, e.g. addictions or palliative care, and could prove useful for interprofessional training programs [8].

\section{Conclusions}

Our web-based training course on CRC screening for GPs was chosen by a majority of GPs and well accepted compared to the face-to-face program. Participating GPs declared their knowledge and skills in the areas of CRC screening and patient-centered care had improved. Future studies are planned to confirm whether or not the CRC screening participation rate has improved.

\section{Abbreviations}


CRC: Colorectal cancer

GP: General practitioner

\section{Declarations}

Ethics approval and consent to participate:

The FORCEPS study was approved by the CNIL and the CPP Sud Méditerranée. All participants received an information letter

Consent for publication: Not applicable

Availability of data and materials: The datasets used and analyzed during the current study are available from the corresponding author on reasonable request.

Competing interests: The authors declare that they have no competing interests.

Funding: we received funding from the French National Cancer Institute for this study.

Authors' contributions: $A A E, B C, B F, J L B$ and IAA participated to the conception and the design of the study. $A A E, A B, K S$ and IAA created the e-learning and analyzed the data. All authors contributed in writing the manuscript. All authors read and approved the final manuscript.

Acknowledgements: We thank the French College of General Practice for its support.

\section{References}

1. Viguier J, Calazel-Benque A, Eisinger F, Pivot X. Organized colorectal cancer screening programmes: how to optimize efficiency among general practitionners. European Journal of Cancer Prevention 2011; 20:26-32.

2. Lauby-Secretan, B., Vilahur, N ., Bianchini, F,Guha N, and Straif, KM.P.for the International Agency for Research on Cancer Handbook Working Group. The IARC perspective on Colorectal Cancer screening. NEJM $2018 ; 378: 1734-40$.

3. Von Karsa L, Anttila A, Ronco G et al. Cancer screening in the European Union : report on the implementation of the Council Recommandation of cancer screening.European communities $2008 \mathrm{http}: /$ / ec europe eu/ health/ ph_determinants/ genetics/ documents/ cancer_screeningpdf2009

4. Le Breton J, Journy N, Attali C, Le Corvoisier P, Brixi Z, Bastuji-Garin S, Chevreul K. Improving participation in colorectal cancer screening: targets for action. Prev Med. 2012 Nov;55(5):488-92. doi: 10.1016/j.ypmed.2012.08.004. Epub 2012 Aug 21. 
5. Aubin-Auger I, Mercier A, Le Bel J, Bombeke K, Baruch D, Youssefian A, Lebeau JP, Le Trung T, Peremans L,Van Royen P. From qualitative data to GP training on CRC screening. J Cancer Educ 2013 ;28:439-43.

6. Aubin-Auger I, Laouénan C, Le Bel J, Mercier A, Baruch D, Lebeau JP, Le Trung T, Youssefian A, Peremans L, Van Royen P. Efficacy of communication skills on colorectal cancer screening by GPs: a cluster randomized control trial. Eur J Cancer Care. 2016 Jan ;25(1):18-2

7. Vaona A, Banzi R, Kwag KH, Rigon G, Cereda D, Pecoraro V, Tramacere I, Moja L.

E-learning for health professionals. Cochrane Database of Systematic Reviews 2018, Issue 1. Art. No.: CD011736.DOI: 10.1002/14651858.CD011736.pub2.

8. Wittenberg-Lyles E, Goldsmith J, Ferrell B, Burchett M. Assessment of an interprofessional online curriculum for palliative care communication training. J Palliat Med. 2014 Apr;17(4):400-6. doi: 10.1089/jpm.2013.0270. Epub 2014 Jan 8.

9. Cogbill, S., Francis, B. \& Thompson, V.L.S. Factors Affecting African American Men's Use of Online Colorectal Cancer Education. J Canc Educ 2014 ; 29 :25-29 https://doi.org/10.1007/s13187-013-0532-7.

10. Barlet M., Marbot C. 2016. Portrait des professionnels de santé. Collection Panoramas de la Drees Santé, avril 2016, 160 p. https://drees.solidarites-sante.gouv.fr/IMG/pdf/gfs-2016_mel_301117.pdf. Accessed 03 septembre 2020

11. Justin Reich. Big Data MOOC Research Breakthrough: Learning Activities Lead to Achievement.March 30, 2014. https://www.edweek.org/education/opinion-big-data-mooc-research-breakthrough-learningactivities-lead-to-achievement/2014/03.

12. Wutoh R, Boren SA, Balas A. elearning: A Review of Internet-Based Continuing Medical Education. J Contin Educ Health Prof. 2004 Winter;24(1):20-30.

13. Regmi K., Jones L. A systematic review of the factors-enablers and barriers-affecting e-learning in health sciences education. BMC Medical Education (2020) 20:91.

\section{Figures}




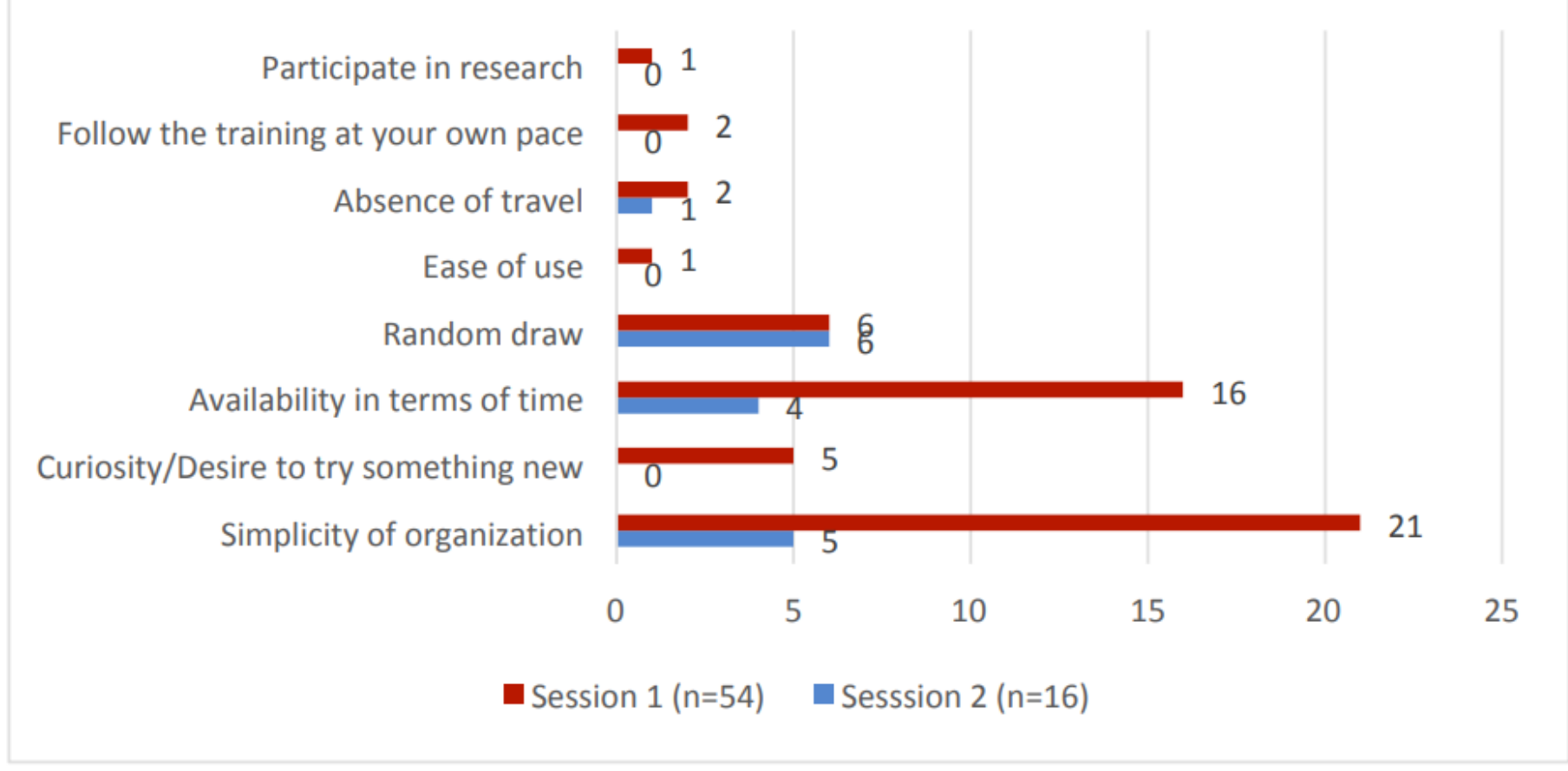

\section{Figure 1}

Why take part in e-learning?

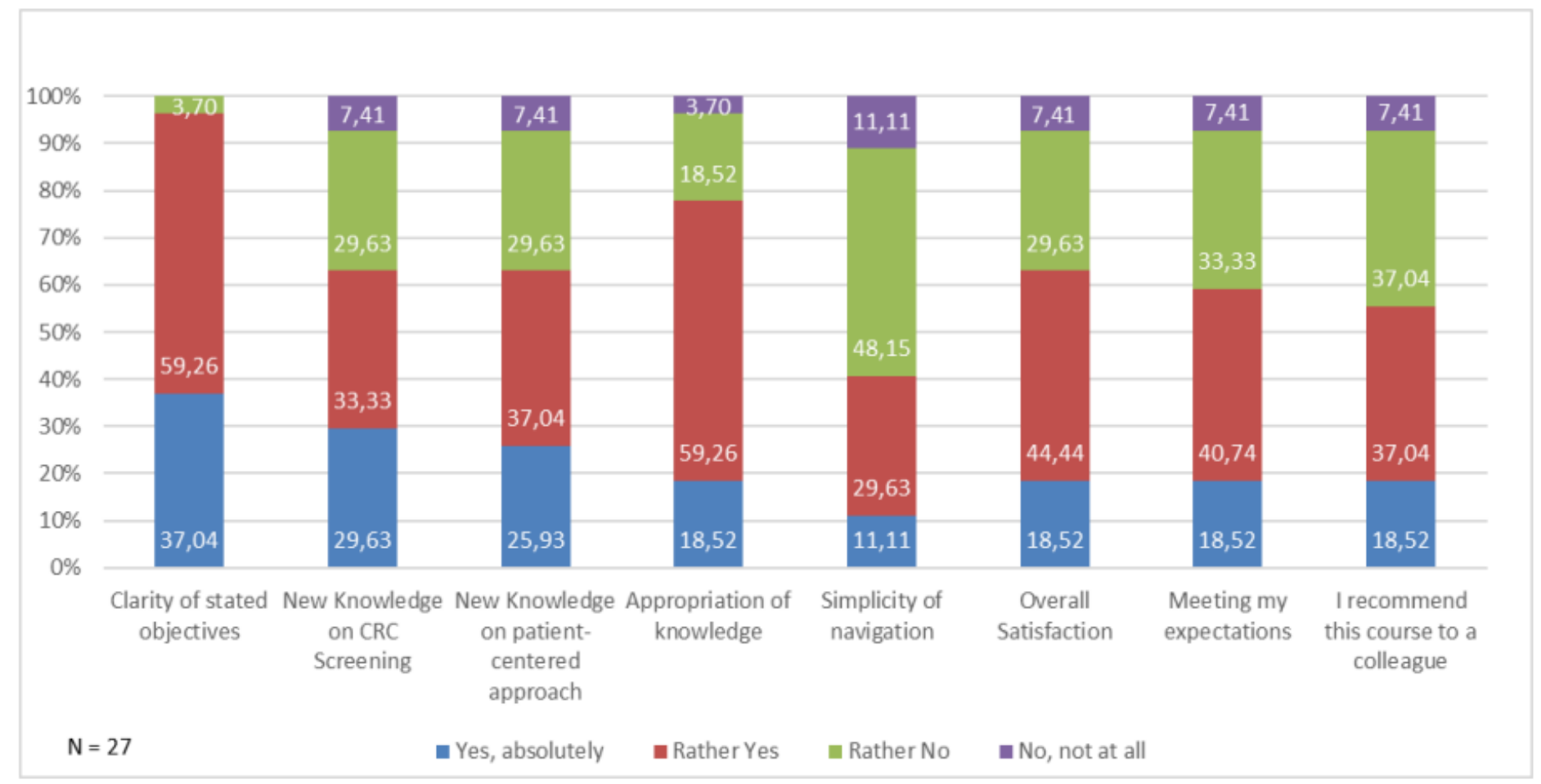

Figure 2

Evaluation of training by participants 